\title{
Interactive comment on "Coupling of a sediment diagenesis model (MEDUSA) and an Earth system model (CESM1.2): a contribution toward enhanced marine biogeochemical modelling and long-term climate simulations" by Takasumi Kurahashi-Nakamura et al.
}

\section{Anonymous Referee \#1}

Received and published: 3 November 2019

This paper developed the coupled system of sediment processes with the earth system using a sediment model (MESUDA) and a state-of-the-art fully coupled atmosphereocean-sea ice-land model (CESM1.2), and then diagnosed the sediment composition contents under the modern ocean conditions. Surprisingly, the comparison between the coupled and the uncoupled system between ocean and sediment processes shows a substantial difference in stable carbon isotope concentrations in some regions of coastal regions and the equatorial Pacific, which suggests that the sediment interaction

Printer-friendly version

Discussion paper 
with bottom ocean waters affects the distributions of stable carbon isotopes as well as other biogeochemical compositions. This result indicates the importance of the coupled system between ocean and sediment for the biogeochemical simulation over millennial time scales. In addition, while the previous model studies applied for the coupling of a sediment model with earth system models of intermediate complexity, this study couples the sediment model with the state-of-the-art comprehensive climate model. This development is technically advanced. I recommend for publication within minor revision. My comments and suggestions regarding the evaluation of the model's capability are as follows.

Major comments

(1) Large differences in sediment contents between two experiments

The paper shows the diagnosed sediment contents of opal and organic carbon are very different in the coupled (EXCPL) and uncoupled (EXOGR) ocean-sediment system (Figs. 5a,c and $6 \mathrm{~b}-\mathrm{c}$ ). Why is the difference so large between the two experiments? I expect that the sediment contents should be relatively similar in two experiments, as shown by the relative similarity in $\mathrm{CaCO} 3$ sediments (Figs. $2 \mathrm{a}$ and $6 \mathrm{a}$ ), because the sedimentation feedback seems to be small in the broad ocean expect the North Atlantic (Fig 7).

I wonder whether the total concentrations of silicate and nutrient are conserved in EXCPL. It may be helpful to provide a table that presents the global integrated deposition fluxes of opal, $\mathrm{CaCO} 3$ and $\mathrm{OC}$ and the global integrated concentrations of DIC, ALK, $\mathrm{SiO} 3$ or $\mathrm{PO} 4$ in two experiments. I also recommend to add the description how the model treats the riverine inflow and sediment outflow fluxes in Section 2.2. That information is key to understand the experimental design of EXCPL. For example, we can understand whether EXCPL is designed for an open or closed system in the atmosphere, ocean and sediment reservoirs.

Printer-friendly version

(2) The impact of all dissolution of $\mathrm{CaCO} 3$ below $3300 \mathrm{~m}$ depth

Discussion paper 
The $\mathrm{BEC}$ model is coordinated by all dissolution of particulate $\mathrm{CaCO} 3$ in the ocean below 3300 m depth, which probably causes less calcite preservation particularly in the Pacific and Indian Ocean. It would be helpful to discuss the impact of this "fixed lysocline depth" setting to the model performance and behaviors in more details. Does this setting affect excess accumulation of organic matter in the equatorial Pacific? I suspect that less $\mathrm{CaCO} 3$ burial maybe cause slower sedimentation rate, which may expose $\mathrm{OC}$ at the upper sediments on longer timescale and thus accelerate the decomposition of OC in sediments.

(3) What is the difference of sediment coupling with the state-of-the-art earth system model with previous studies with intermediate complexity models?

I think it is helpful to discuss the advantage using the state-of-the-art earth system model. What is a large difference in simulations between CESM-MESUDA and for example, GENIE? What does this development help our better understanding?

\section{Minor comments:}

Table1: This table is very good and informative to provide the model's capability from the model-data comparison. It may be also helpful to add the deposition and burial fluxes, as described above in my comment (1).

Page 3 L31-33: This description is unclear. Does it mean that all burial fluxes return to the bottom water as dissolved properties? Please rewrite the description.

Page 8 L5-6: This sentence is also unclear. Do you want to say that the oceansediment coupling is important to simulate the water properties? Please rephrase it to present your argument more clearly.

Page 9 Line29: "over large areas" maybe mislead readers. In this paper, the sediment feedback is apparent in some regions, such as along the east coast of the equatorial Pacific, along the west coast of the Pacific, in the Arctic and Hudson Bay. Rather, the large difference in $\mathrm{d} 13 \mathrm{C}$ in the North Atlantic arises from the model's bias in relation

Printer-friendly version

Discussion paper 
to AMOC or ocean mixing variability, which should be excluded from the sediment contributions to the bottom-water properties.

Page 10 L29: provides $\rightarrow$ provide

Interactive comment on Geosci. Model Dev. Discuss., https://doi.org/10.5194/gmd-2019-231, 2019. 